\title{
Prevalence, diagnosis, and management of iron deficiency and iron deficiency anemia among Syrian children in a major outpatient center in Damascus, Syria
}

\author{
Issam N. Albaroudi ${ }^{1}$, Majed Khodder ${ }^{2,3}$, Tareq Al Saadi ${ }^{4}$, Tarek Turk ${ }^{4}$, Lama A. Youssef ${ }^{1}$ \\ ${ }^{1}$ Program of Clinical and Hospital Pharmacy, Department of Pharmaceutics and Pharmaceutical Technology, School of Pharmacy, \\ Damascus University, ${ }^{2}$ Department of Hematology, Children's Hospital, ${ }^{3}$ Department of Pediatrics, Faculty of Medicine, Damascus University, \\ ${ }^{4}$ Department of Internal Medicine, Damascus University, Damascus, Syria
}

\begin{tabular}{|c|}
\hline Access this article online \\
\hline Website: www.avicennajmed.com \\
\hline DOI: 10.4103/ajm.AJM_169_17 \\
\hline Quick Response Code: \\
\hline
\end{tabular}

\section{ABSTRACT}

Background: Given the public health significance of anemia, the long-term sequelae of iron deficiency anemia (IDA) on children, the expected effect of war on the trends of anemia in Syrian society, and the lack of assessment on the national burden of anemia and/or iron deficiency (ID) data, there is a vital need to investigate all-cause anemia, ID, and IDA in Syria during the crisis. Objective: To investigate the prevalence of ID and IDA in Syrian children, the effectiveness of oral iron supplements in the management of ID, and the diagnostic effectiveness of conventional iron markers. Methods: We conducted a retrospective study on hemoglobin $(\mathrm{Hb})$ levels in 4-month-old to 14-year-old children and a prospective study on hematological (complete blood count, reticulocytes, and reticulocyte $\mathrm{Hb}$ content) and biochemical iron indices (serum ferritin, iron, and total iron-binding capacity) of infants visiting the primary care clinic at Children's Hospital in Damascus, Syria. Results: Of the 1128 children in the retrospective study, 648 children (57\%) were found to be anemic, with 417 (37\%) moderately-severely anemic. The prevalence of ID and IDA in the 135 children of the prospective study was $71.85 \%$ and $55.55 \%$, respectively. Infants with ID who underwent a 4-8-week course of oral iron supplementation demonstrated good responsiveness. Except mean corpuscular hemoglobin ( $\mathrm{MCH})$, conventional iron markers (i.e., ferritin) routinely used to assess iron status proved unreliable. Conclusion: This study reveals a high prevalence of anemia, ID, and IDA among a group of apparently healthy Syrian children. Our findings necessitate a framework of urgent public health interventions that can address two major limitations; the poor follow-up by the parents and unreliability of the conventional iron diagnostic markers. $\mathrm{MCH}$ may represent a simple and cheap ID screening index in children.

Key words: Anemia, infants, iron deficiency, Syria, Syrian crisis

\section{INTRODUCTION}

Anemia is a public health problem that is widely prevalent worldwide. It has major consequences on individuals' well-being and the socioeconomic development of societies. ${ }^{[1,2]}$ The World Health Organization (WHO)

Address for correspondence: Dr. Lama A. Youssef, School of Pharmacy, Damascus University, Mezzeh Autostrade, Damascus, Syria.

E-mail: ylama@hotmail.com
This is an open access journal, and articles are distributed under the terms of the Creative Commons Attribution-NonCommercial-ShareAlike 4.0 License, which allows others to remix, tweak, and build upon the work non-commercially, as long as appropriate credit is given and the new creations are licensed under the identical terms.

For reprints contact: reprints@ medknow.com

Cite this article as: Albaroudi IN, Khodder M, Al Saadi T, Turk T, Youssef LA. Prevalence, diagnosis, and management of iron deficiency and iron deficiency anemia among Syrian children in a major outpatient center in Damascus, Syria. Avicenna J Med 2018;8:92-103. 
estimated that approximately $25 \%$ of the earth's population is anemic. ${ }^{[2]}$ Anemia can be attributed to a wide variety of etiologies, such as malnutrition, acute and chronic infections, and genetic hemoglobin $(\mathrm{Hb})$ defects. ${ }^{[2,3]}$

Iron deficiency (ID) is the most common malnutrition disorder around the world. ${ }^{[4]}$ It accounts for $50 \%-60 \%$ of all anemia cases. ${ }^{[2]}$ Many risk factors are accused of depleting iron stores in the body, including insufficient dietary intake, malabsorption disorders, helminthic infections, chronic and acute blood loss, and increased body demands. ID anemia (IDA) is most prevalent during periods of rapid body growth, and its long-term effects are especially prominent in infants. ${ }^{[5]}$ IDA can lead to devastating, potentially irreversible consequences in young children if left undiagnosed and/or untreated. These consequences may include developmental delay, general weakness, and learning disabilities. ${ }^{[6,7]}$

An IDA diagnosis can be established using a set of serological and biochemical tests, including ferritin, serum iron, transferrin saturation (TSAT), and total iron-binding capacity (TIBC). However, these iron parameters can be affected by several physiological and pathological states, including inflammations, infections, dietary intake, and circadian rhythm, which limit their diagnostic value. ${ }^{[8]}$ Reticulocyte hemoglobin content $(\mathrm{CHr})$ has recently emerged as a more reliable parameter to monitor iron stores and reflect the bioavailability of iron. ${ }^{[8,9]}$

Infants and young children in developing countries are particularly vulnerable to ID due to a negative iron balance resulting from increasing demands for growth that surpass dietary supplies. ${ }^{[10]}$ This effect might be more profound in Syria where a devastating war has been damaging all sectors of life for $>6$ years. Reports have shown that displacement, deteriorating standards of living, and the soaring price of food have forced many families to decrease their intake of the most nutritious foods. ${ }^{[11,12]}$ Therefore, the rates of anemia, especially IDA, are expected to increase in children due to shortages of food and medications.

Given the public health significance, the long-term sequelae of IDA on children, the expected effect of war on the trends of anemia in Syrian society, and the lack of assessment on the national burden of anemia and/or ID data, we decided to investigate the prevalence of all-cause anemia, ID, and IDA in a population of apparently healthy Syrian children. Moreover, we intended to describe the epidemiological characteristics, risk factors that render Syrian children vulnerable to ID during the crisis, and to investigate the effectiveness of oral iron supplements in the management of ID and parents' compliance. Furthermore, taking into consideration the importance of early diagnosis of IDA in infants, we aimed through this study to assess the diagnostic effectiveness of the conventional hematological and biochemical markers compared to $\mathrm{CHr}$.

\section{METHODS}

\section{Study design}

This project consists of two parts: a retrospective study and a prospective study. In the retrospective study, where the primary objective was to investigate anemia in general, we reviewed the charts of all apparently healthy children older than 4 months of age who visited the primary care clinics at the Children's Hospital in Damascus, Syria, during the period from November 2011 to November 2015. We attempted to extract all available data regarding the demographic characteristics (age, sex, and residence), chief complaints and diagnosis, and hematological indices of the children, given that all children presenting at the outpatients' clinic normally receive complete blood count (CBC) test.

In the prospective study, where the main goal was to investigate latent ID (LID) and IDA, we calculated the prevalence of LID and IDA in children aged between 4 and 26 months, who visited the primary care clinics at the Children's Hospital in Damascus, Syria. We assessed all patients who presented to the clinics over a period of 2 months for potential inclusion in our study. Children with a history of anemia other than IDA or with family history of thalassemia, sickle cell anemia, or favism were subjected to further investigation that included $\mathrm{Hb}$ electrophoresis and glucose-6-phosphate dehydrogenase (G6PD) assessment to confirm or refute anemia etiologies other than ID.

\section{Ethicall issues}

Ethical approval of this study was granted by the Ethics Committee of the Faculty of Pharmacy, Damascus University, Damascus, Syria. After our provision of a thorough explanation of the study objectives and procedures, parents of eligible infants who agreed to participate in the study provided informed consent.

\section{Inclusion and exclusion criteria}

We included children who appeared healthy on primary physical examination. We excluded all children with systemic diseases that can cause an anemic profile such as renal or hepatic failure, malignancies, thyroid dysfunction, ketoacidosis, bleeding, congenital hematological disorders, and growth failure. In addition, we excluded those who received a blood transfusion within the 3 months before measuring the hematological and biochemical indices. 


$\begin{aligned} & \text { Table I: Children's hematological indices (retrospective } \\
& \text { study) }\end{aligned}$
\begin{tabular}{lccc} 
& & \\
\hline $\mathrm{Hb}(\mathrm{g} / \mathrm{dL})$ & $10.54 \pm 1.95$ & 4.9 & 15.5 \\
$\mathrm{MCV}(\mathrm{fl})$ & $75.29 \pm 9.47$ & 27.7 & 116 \\
Platelets count $(/ \mathrm{ml})$ & $386,164 \pm 164,996$ & 51,000 & 941,000 \\
\hline Hb: Hemoglobin, MCV: Mean corpuscular volume, SD: Standard deviation
\end{tabular}

\section{Data collection}

For the retrospective study, we extracted all available data from patients' chart including the aforementioned demographic data, and the outcomes are stated in Table 1.

For the prospective study, parents were personally interviewed to complete a form that collects information regarding their child's demographic characteristics (including age, gender, and place of birth), type of milk that is used to feed the child (maternal, cow milk, iron-fortified formula, or a mixture of these types), and residence (cities or suburbs). Some ID-associated symptoms (including irritability, mood swings, and loss of appetite) were investigated by asking the parents if they noticed that their child had any abnormal irritability/mood swings/loss of appetite. We measured each child's height, weight, and skull circumference. In addition, we performed hematological studies including ( $\mathrm{CBC}$, reticulocyte count, and $\mathrm{CHr}$ ) and biochemical studies (serum iron, TIBC, ferritin, and TSAT). Furthermore, we assessed the growth of the enrolled children by recording a single measurement of length, weight, and skull circumference (measured at the initial visit as mentioned earlier) using the WHO growth charts for comparison and via calculating length-to-age, weight-to-age, skull circumference-to-age, and weight-to-length ratios.

We used ADVIA 120 Hematology System (Bayer Diagnostics, Tarrytown, USA) to measure hematological markers including $\mathrm{CBC}$, reticulocytes count, and $\mathrm{CHr}$. For biochemical assays, we measured serum iron and TIBC using the Hitachi 912 Analyzer (Roche Diagnostics, Geneva, Switzerland) and assessed ferritin level using LIAISON Analyzer (DiaSorin, Italy).

\section{Diagnosis and classification}

ID and IDA were diagnosed according to the 2010 American Academy of Pediatrics for determining the iron status in the children of prospective study. ${ }^{[13]}$ According to these guidelines, ID without anemia (i.e., LID) is diagnosed when $\mathrm{Hb} \geq 11 \mathrm{~g} / \mathrm{dl}$ and $\mathrm{CHr}<26 \mathrm{pg}$, whereas IDA is diagnosed when $\mathrm{Hb}<11 \mathrm{~g} / \mathrm{dl}$ and $\mathrm{CHr}<26 \mathrm{pg}$, after adjustment for age of the children. We assessed the severity of anemia in the study participants based on the WHO classification ${ }^{[14]}$ that classifies anemia into three categories; mild, moderate, and severe according to $\mathrm{Hb}$ cutoff values in three childhood age subgroups; 6-59 months, 5-11 years, and 12-14 years. After assessment and adjustment for age, all anemic cases were pooled to calculate the overall prevalence.

To correct LID and IDL and to evaluate the therapeutic effectiveness of the commercially available iron treatments in the local market during the crisis, we provided oral iron therapy free-of-charge to parents of all children who were diagnosed with LID or IDA based on their $\mathrm{Hb}$ and $\mathrm{CHr}$ levels. Children were given $5-6 \mathrm{mg} / \mathrm{kg}$ of ferrous sulfate (elemental iron) daily through liquid iron for 3 months. Parents were also provided with information and instructions concerning the usage and dosage, orally and written. To evaluate the therapeutic outcomes, enrolled children were scheduled for follow-up every 4 weeks, for a total period of 6 months. All previously mentioned hematological and biochemical tests were repeated at each subsequent visit.

\section{Statistic al analysis}

Data were analyzed using Microsoft Office Excel 2007 and GraphPad Prism version 6.00 for Windows (GraphPad Software Inc., La Jolla, California, USA). A $P<0.05$ was considered the level of statistical significance in all statistical tests. Participants' characteristics were reported as frequencies and percentages (for categorical variables) or means and standard deviations (for continuous variables). To investigate the statistical significance of the differences in demographic characteristics and hematological and biochemical indices between health, LID, and IDA subgroups, we used the Fisher's exact test or Chi-square test (for categorical variables) and $t$-test or unilateral ANOVA (for continuous variables). We also used $t$-test to investigate the statistical significance of the differences in hematological and biochemical indices before and after management. For the assessment of the different hematological and biochemical diagnostic parameters in reference to $\mathrm{CHr}$ as the standard test, we calculated the sensitivity and specificity of each of the hematological and biochemical tests using the receiver operating characteristic (ROC) curves. Spearman correlation was calculated to evaluate correlation between the investigated hematological and biochemical indices.

\section{RESULTS}

\section{Results of the retrospective study}

Initially, we assessed the charts of 1167 children who were potentially eligible and underwent laboratory testing for the investigated indices. We excluded 39 children based on the exclusion criteria detailed in the Methods section. Overall, 1128 children were included in the study. The process is summarized in Figure 1. 


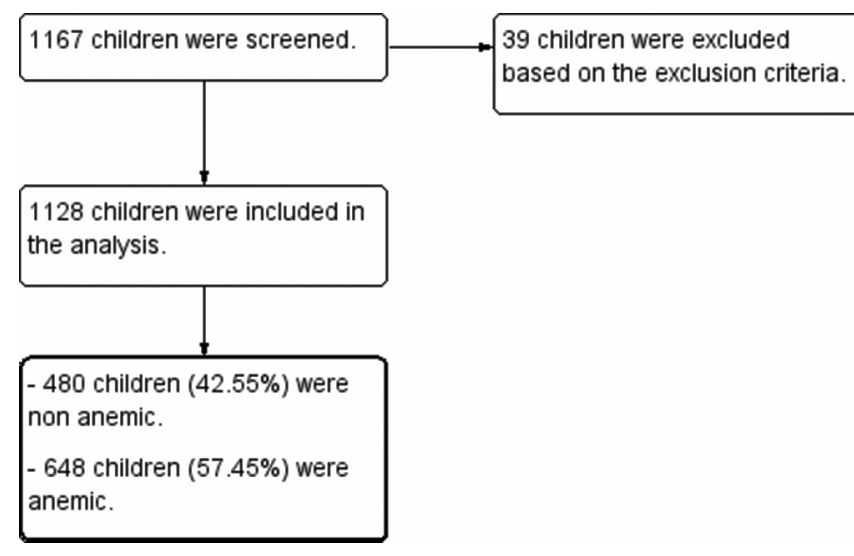

Figure 1: A flowchart of the retrospective study

Unfortunately, the majority of charts did not document detailed demographic characteristics or lacked some hematological indices. We could only extract data relating to basic demographic characteristics (age, gender, and residence) and general hematological indices ( $\mathrm{Hb}, \mathrm{MCV}$, and platelets count) of the participants, and thus, we could only investigate all-cause anemia for this retrospective study.

The sample encompassed 651 males (57.71\%) and 477 females (42.29\%). Ages ranged from 4 months to 14 years, with a mean ( \pm standard deviation) of 42 months $( \pm 41)$ months. Families of most included children (79.34\%) lived in the suburbs. The mean $\mathrm{Hb}$ for the included children was $10.54 \mathrm{~g} / \mathrm{dL}$, with a standard deviation of $1.95 \mathrm{~g} / \mathrm{dL}$. Other hematological indices are summarized in Table 1. More than half of the included children were anemic (648 children, 57.45\%). Applying the previously cited WHO's classification for the assessment of severity of anemia on our sample revealed that approximately $50 \%$ of the anemic children had moderate anemia, whereas about $10 \%$ had severe anemia [Figure 2].

There was neither statistically significant difference in the prevalence of anemia between males and females $(P=0.8)$ nor between children who lived in suburbs and those who lived in Damascus city $(P=0.88)$ [Table 2]. However, when the children were categorized based on age subgroups, the prevalence of anemia was higher $(74 \%)$ in the oldest children group (12-14 years [ $n=58]$ ), in comparison with $56 \%$ and $58 \%$ in the up to 59 months $(n=825)$ and the $5-11$ years $(n=245)$ groups, respectively.

\section{Results of the prospective study}

We assessed 155 infants (4-26 months) for eligibility. Ten families refused to participate in the study, and ten children were excluded according to the exclusion criteria and therefore were not evaluated. The recruitment process is summarized in Figure 3.

\begin{tabular}{|c|c|c|c|}
\hline & Nonanemic & Anemic & $P$ \\
\hline \multicolumn{4}{|l|}{ Gender, $n(\%)$} \\
\hline Male & $275(42.25)$ & $376(57.75)$ & 0.8 \\
\hline Female & $205(47.4)$ & $272(52.6)$ & \\
\hline \multicolumn{4}{|l|}{ Residence, $n$ (\%) } \\
\hline Damascus city & 98 (42.07) & $135(57.93)$ & 0.88 \\
\hline Damascus suburbs & $382(42.69)$ & $5 I 3(57.3 I)$ & \\
\hline
\end{tabular}

Overall, the study included 135 infants. Data revealed that only 31 children (22.96\%) were nonanemic and noniron deficient, whereas $22(16.3 \%)$ children had LID and $75(55.55 \%)$ children suffered IDA. Thus, more than two-thirds of children $(n=97,71.85 \%)$ had ID, with or without anemia. In addition, four children (2.96\%) were diagnosed with $\beta$-thalassemia trait confirmed by $\mathrm{Hb}$ electrophoresis, two children (1.48\%) were diagnosed with macrocytic anemia (B12 deficiency), and one child (0.74\%) was diagnosed with hemolytic anemia (G6PD deficiency). After excluding non-ID anemic children $(n=7)$, only 128 children were included in the analysis.

Comparing age, weight, and hematological and biochemical indices between $\mathrm{Hb} /$ iron normal children, children with LID, and children with IDA revealed statistically significant differences in the values of $\mathrm{Hb}, \mathrm{HCT}, \mathrm{MCV}$, mean corpuscular hemoglobin $(\mathrm{MCH}), \mathrm{CHr}$, serum iron, TSAT, and red cell distribution width (RDW). However, the differences in age, weight, TIBC, ferritin, or platelets count were not statistically significant [Table 3]. The prevalence of irritability, mood swings, loss of appetite, and Pica syndrome in children with ID (with or without anemia) was $37 \%$, $36 \%, 24 \%$, and $12.5 \%$, respectively. Comparison of children who were fed iron-fortified formula with those who were depended on noniron-fortified milk (exclusive breastfeeding, cow milk, or both) revealed that the prevalence of LID was higher in children who were fed noniron-fortified milk (80.95\%) compared to those consuming iron-fortified milk (70.76\%). However, this difference was not statistically significant $(P=0.21)$.

The prevalence of ID (with or without anemia) was $85.33 \%$ in males and $62.26 \%$ in females. Males had significantly higher prevalence of ID compared to females $(P=0.004)$ [Table 4]. Furthermore, the prevalence of IDA in children whose families live in the suburbs of Damascus (62.89\%) was significantly higher compared to those whose families live in Damascus city (45.16\%) $(P=0.04)$ [Table 4].

Both the LID and IDA subgroups had a significantly higher proportion of children with abnormal weight-to-age ratio 


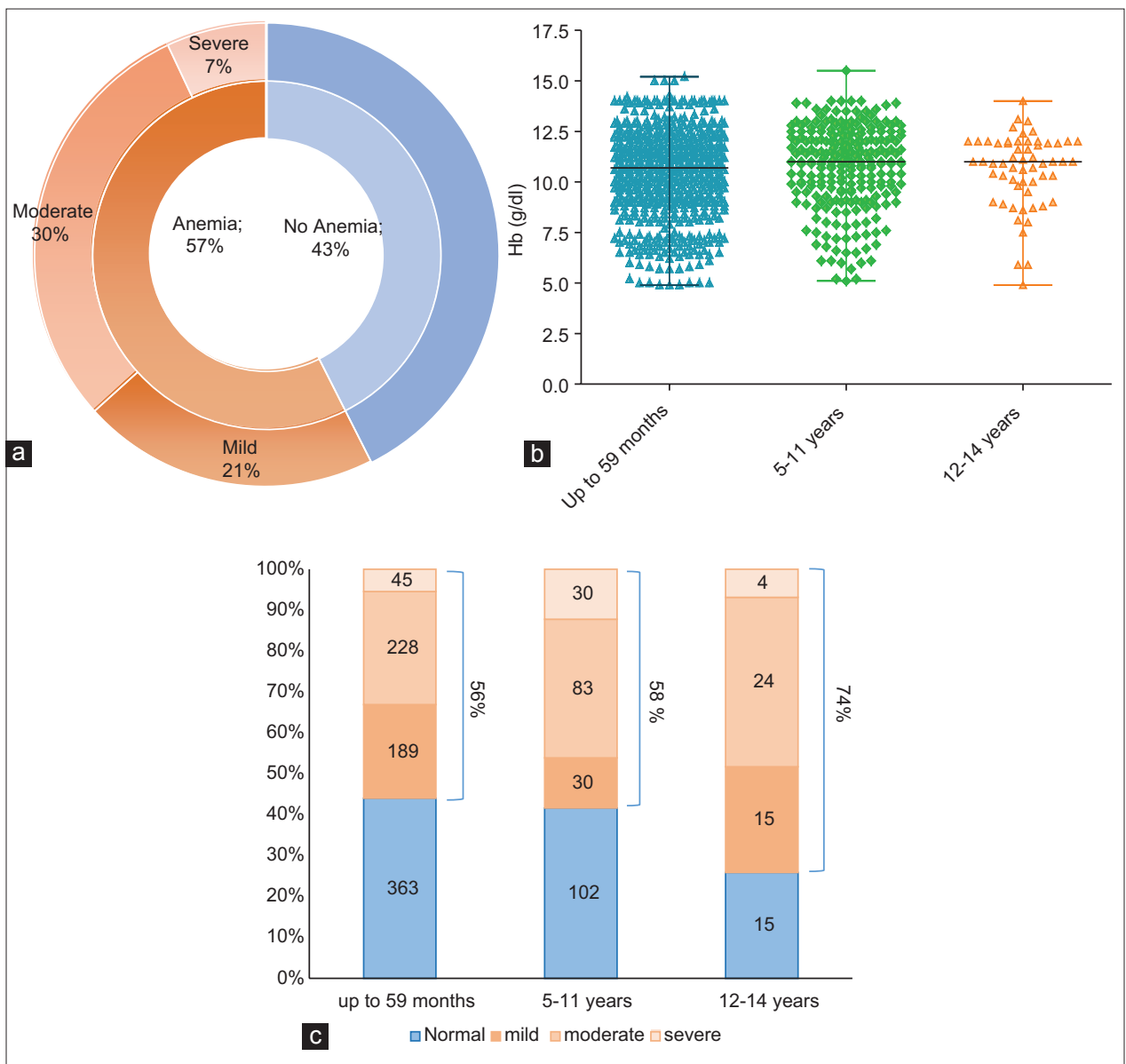

Figure 2: (a) Prevalence of anemia severity defined according to the WHO criteria. (b) Distribution of hemoglobin concentrations in the study age groups. (c) Severity of anemia according to the WHO criteria in the study age groups

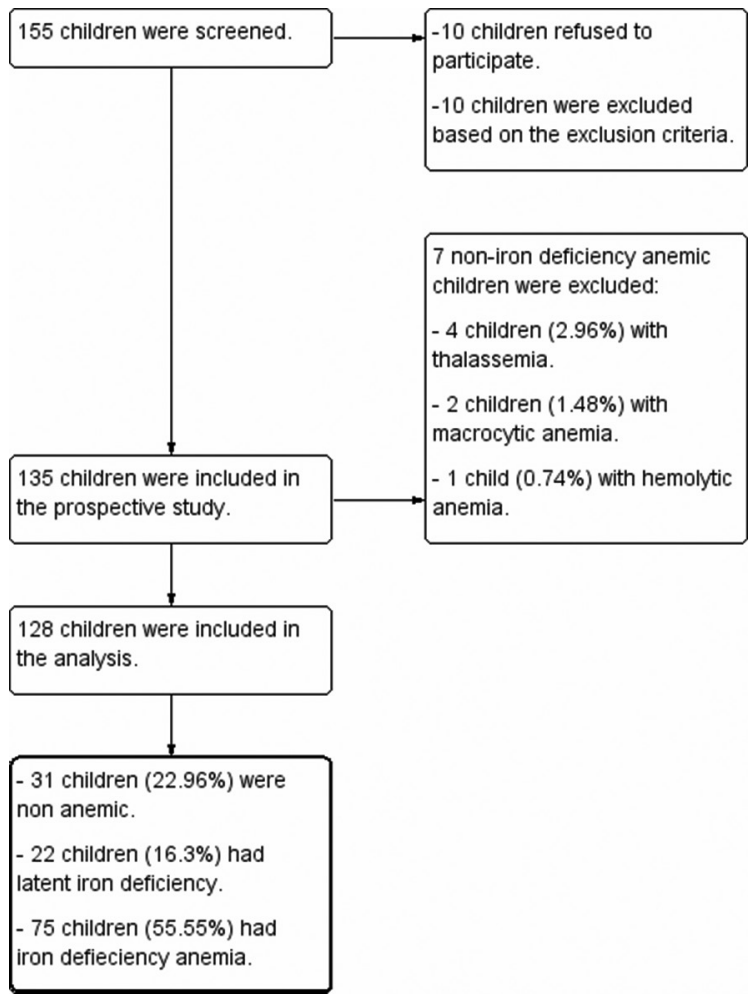

Figure 3: A flowchart of the recruitment process for the prospective study compared to nonanemic children $(P=0.04$ and 0.05 , respectively). There were no significant differences between LID, IDA, and nonanemic subgroups when comparing other growth ratios [Table 5].

Investigating the effect of some socioeconomic factors on the prevalence of LID revealed only few significant relationships [Table 6]. The results, however, showed that IDA was significantly lower in small families ( 3 members) compared to those with $\geq 5$ members $(P=0.04)$, in families who resided in a house with two rooms compared to houses with $\geq 3$ rooms $(P=0.04)$, and in families with only one child compared to families with $\geq 3$ children $(P=0.05)$ [Table 7].

\section{Effectiveness of iron therapy}

We were not able to follow-up all the iron-deficient children due to poor compliance of parents with clinic visits. This could be attributed, at least in part, to the unfortunate circumstances in the country during the study and the hardships of reaching care centers. We were able to follow 37 children up to 4 weeks and 11 children for 8 weeks. 


\begin{tabular}{|c|c|c|c|c|}
\hline & Iron sufficient $(n=31)$ & LID $(n=22)$ & IDA $(n=75)$ & $P$ \\
\hline Age (months) & $12.77 \pm 6.3$ & $11.9 \pm 5.56$ & $12.27 \pm 5.54$ & 0.85 \\
\hline Weight (kg) & $7.88 \pm 1.87$ & $8.47 \pm 1.93$ & $8.67 \pm 1.82$ & 0.14 \\
\hline $\mathrm{Hb}(\mathrm{g} / \mathrm{dL})$ & $11.9 \pm 0.72$ & $|1.79 \pm 0.8|$ & $9.69 \pm 1.05$ & $<0.0001 *$ \\
\hline $\mathrm{HCT}(\%)$ & $34.72 \pm 2.33$ & $35.42 \pm 2.24$ & $31.07 \pm 3.18$ & $<0.0001 *$ \\
\hline$M C V(f L)$ & $78.89 \pm 3.99$ & $75.25 \pm 3.51$ & $66.87 \pm 7.98$ & $<0.0001 *$ \\
\hline $\mathrm{MCH}(\mathrm{pg})$ & $26.89 \pm 1.63$ & $25.09 \pm 1.8$ & $21.35 \pm 2.89$ & $<0.0001 *$ \\
\hline $\mathrm{CHr}(\mathrm{pg})$ & $27.02 \pm 0.85$ & $24.16 \pm 2.32$ & $21.53 \pm 2.52$ & $<0.0001 *$ \\
\hline Serum iron $(\mathrm{mmol} / \mathrm{L})$ & $9 \pm 5.74$ & $4.91 \pm 3.26$ & $3.76 \pm 3.07$ & $<0.001 *$ \\
\hline TIBC ( $\mu \mathrm{mol} / \mathrm{L})$ & $75.6 \pm 9.09$ & $66.3 \pm 10.99$ & $73.24 \pm 15.05$ & 0.32 \\
\hline TSAT (\%) & $|3.9 \pm 1|$ & $7.93 \pm 4.93$ & $4.62 \pm 4.44$ & $0.003 *$ \\
\hline Ferritin $(\mathrm{ng} / \mathrm{mL})$ & $33.68 \pm 22.11$ & $37.23 \pm 21$ & $40.70 \pm 56.70$ & 0.93 \\
\hline $\operatorname{RDW}(\%)$ & $|4.8| \pm 2.19$ & $14.52 \pm 1.28$ & $16.76 \pm 1.94$ & $<0.000 I^{*}$ \\
\hline Platelets count $\left(\times 10^{3} / \mu \mathrm{L}\right)$ & $468.888 \pm 152.747$ & $425.470 \pm 128.708$ & $445.517 \pm 147.05 \mid$ & 0.61 \\
\hline
\end{tabular}

\begin{tabular}{|c|c|c|c|}
\hline \multicolumn{4}{|c|}{$\begin{array}{l}\text { Table 4: Prevalence of iron deficiency and } \\
\text { anemia according to children's demographic } \\
\text { characteristics (prospective study) }\end{array}$} \\
\hline & Iron sufficient, $n$ (\%) & LID, $n$ (\%) & IDA, $n(\%)$ \\
\hline \multicolumn{4}{|l|}{ Gender } \\
\hline Male $(n=75)$ & II (I4.7) & $13(17.3)$ & $51(68)$ \\
\hline Female $(n=53)$ & $20(37.74)$ & $9(16.98)$ & $24(45.28)$ \\
\hline \multicolumn{4}{|l|}{ Residence } \\
\hline $\begin{array}{l}\text { Damascus city } \\
(n=31)\end{array}$ & $12(38.7 \mathrm{I})$ & $5(16.13)$ & $14(45.16)$ \\
\hline $\begin{array}{l}\text { Damascus } \\
\text { suburbs }(n=97)\end{array}$ & 19 (19.59) & $17(17.53)$ & 61 (62.89) \\
\hline
\end{tabular}

\begin{tabular}{|c|c|c|c|c|c|}
\hline & $\begin{array}{c}\text { Iron } \\
\text { sufficient }\end{array}$ & LID & IDA & $\begin{array}{l}\text { LID versus } \\
\text { nonanemic }\end{array}$ & $\begin{array}{l}\text { IDA versus } \\
\text { nonanemic }\end{array}$ \\
\hline \multicolumn{6}{|c|}{ Length-to-age } \\
\hline Normal & 14 & 14 & 49 & 0.26 & 0.08 \\
\hline Abnormal & 17 & 8 & 26 & & \\
\hline \multicolumn{6}{|c|}{ Weight-to-age } \\
\hline Normal & 13 & 16 & 48 & $0.04 *$ & $0.05^{*}$ \\
\hline Abnormal & 18 & 6 & 27 & & \\
\hline \multicolumn{6}{|c|}{$\begin{array}{l}\text { Skull } \\
\text { circumflex-to-age }\end{array}$} \\
\hline Normal & 18 & 16 & 50 & 0.38 & 0.5 \\
\hline Abnormal & 13 & 6 & 25 & & \\
\hline \multicolumn{6}{|c|}{ Weight-to-length } \\
\hline Normal & 18 & 16 & 54 & 0.38 & 0.17 \\
\hline Abnormal & 13 & 6 & 21 & & \\
\hline
\end{tabular}

Table 8 summarizes the children's hematological indices at baseline, after 4 weeks, and after 8 weeks of commencing children on iron supplements. The follow-up at these two time-points revealed that children who received oral iron showed significantly higher values of hematological indices ( $\mathrm{Hb}$ and $\mathrm{CHr}$ ) compared to baseline measurements, reflecting potential effectiveness of the treatment.
Evaluating sensitivity and specificity of hematological and biochemical indices for diagnosing latent iron deficiency and iron deficiency anemia compared to reticulocyte hemoglobin content in the prospective study

We calculated values of cutoff points, sensitivity, and specificity for all hematological and biochemical indices that were used in the study based on ROC curves [Table 9]. All of the investigated indices had relatively low sensitivity and specificity, except for MCV and $\mathrm{MCH}$, which showed sensitivity and specificity exceeding $87 \%$ for both in diagnosing IDA. $\mathrm{MCH}$ showed good sensitivity and specificity ( $82 \%$ and $80 \%$, respectively) in diagnosing LID. On the other hand, the sensitivity and specificity of ferritin did not exceed $60 \%$ for diagnosing LID or IDA. Noteworthy, the prevalence of ID in children did not exceed $17.5 \%$ when using the globally endorsed reference value of ferritin $(12 \mathrm{ng} / \mathrm{ml})$, compared to a prevalence that reached $71.53 \%$ when using $\mathrm{CHr}$.

Evaluating the correlations between the hematological and biochemical indices in the prospective study

The Spearman coefficient $(r)$ was calculated to evaluate correlations between the investigated hematological and biochemical indices for all children in the study sample [Table 10]. Hb showed relatively high correlation with $\mathrm{MCV}, \mathrm{MCH}$, and $\mathrm{CHr}(r=0.68,0.74$, and 0.70 , respectively). Furthermore, $\mathrm{MCH}$ showed high correlation with MCV and $\mathrm{CHr}(r=0.77$ and 0.86 , respectively).

\section{Using mean corpuscular hemoglobin in diagnosing} latent iron deficiency and iron deficiency anemia When we investigated the concurrence of values of $\mathrm{MCH}$ and $\mathrm{CHr}$, either normal or decreased below the cutoff point, for all the included children in the study sample, and using 


\begin{tabular}{|c|c|c|c|c|c|}
\hline & $\begin{array}{c}\text { Iron } \\
\text { sufficient } \\
(n=31), n(\%)\end{array}$ & $\begin{array}{c}\text { LID } \\
(n=22), \\
n(\%)\end{array}$ & OR & $95 \% \mathrm{Cl}$ & $P$ \\
\hline \multicolumn{6}{|l|}{ Family members } \\
\hline 3 & $9(29.03)$ & $3(13.63)$ & 0.35 & $0.07-1.59$ & 0.29 \\
\hline 4 & 7 (22.58) & $5(22.72)$ & 0.76 & $0.19-2.98$ & 0.74 \\
\hline$\geq 5$ & 15 (48.39) & $14(63.65)$ & I & & \\
\hline \multicolumn{6}{|l|}{$\begin{array}{l}\text { Number of rooms } \\
\text { in house }\end{array}$} \\
\hline I & $6(19.36)$ & $5(22.73)$ & 0.59 & $0.11-3.10$ & 0.68 \\
\hline 2 & $20(64.5 \mathrm{I})$ & $10(45.45)$ & 0.35 & $0.09-1.41$ & 0.17 \\
\hline$\geq 3$ & $5(16.13)$ & $7(31.82)$ & I & & \\
\hline \multicolumn{6}{|l|}{$\begin{array}{l}\text { Number of children } \\
\text { in family }\end{array}$} \\
\hline 1 & $10(32.26)$ & $4(18.18)$ & 0.4 & $0.09-1.63$ & 0.3 \\
\hline 2 & $9(29.03)$ & $6(27.27)$ & 0.66 & $0.18-2.46$ & 0.74 \\
\hline$\geq 3$ & $12(38.71)$ & $12(54.55)$ & 1 & & \\
\hline \multicolumn{6}{|l|}{ Infants } \\
\hline Term infants & $31(100)$ & $22(100)$ & & & \\
\hline Preterm infants & 0 & 0 & & & \\
\hline \multicolumn{6}{|l|}{ Monthly family } \\
\hline \multicolumn{6}{|l|}{ income (SP) } \\
\hline$<10,000$ & $14(45.16)$ & $14(63.64)$ & 2.12 & $0.69-6.51$ & 0.26 \\
\hline $10,000-20,000$ & $17(54.84)$ & $8(36.36)$ & & & \\
\hline$>20,000$ & 0 & 0 & & & \\
\hline \multicolumn{6}{|l|}{$\begin{array}{l}\text { Paternal educational } \\
\text { attainment }\end{array}$} \\
\hline Illiterate & 0 & $3(13.635)$ & 7 & $0.22-219.1$ & 0.42 \\
\hline Primary & $13(41.94)$ & $13(59.09)$ & I & $0.12-8.21$ & 1 \\
\hline Secondary & $12(38.7 I)$ & $3(13.635)$ & 0.25 & $0.02-2.57$ & 0.27 \\
\hline Higher & $4(12.90)^{\prime}$ & I (4.55) & 0.25 & $0.01-4.73$ & 0.52 \\
\hline Institute/university & $2(6.45)$ & $2(9.09)$ & 1 & & \\
\hline \multicolumn{6}{|l|}{$\begin{array}{l}\text { Maternal educational } \\
\text { attainment }\end{array}$} \\
\hline Illiterate & 0 & 0 & & & \\
\hline Primary & 15 (48.39) & $13(59.09)$ & 1.3 & $0.18-9.02$ & I \\
\hline Secondary & $9(29.03)$ & $6(27.27)$ & I & $0.12-7.89$ & I \\
\hline Higher & $4(12.90)$ & I (4.55) & 0.37 & $0.02-6.35$ & I \\
\hline Institute/university & $3(9.68)$ & $2(9.09)$ & I & & \\
\hline \multicolumn{6}{|l|}{ Type of delivery } \\
\hline Cesarean delivery & II (35.48) & $9(40.90)$ & 1.25 & $0.40-3.87$ & 0.77 \\
\hline Vaginal delivery & $20(64.5 \mathrm{I})$ & $13(59.09)$ & & & \\
\hline \multicolumn{6}{|l|}{ Maternal smoking } \\
\hline Yes & $2(6.45)$ & $5(22.72)$ & 4.26 & $0.74-24.45$ & 0.11 \\
\hline No & $29(93.54)$ & 17 (77.27) & & & \\
\hline
\end{tabular}

the cutoff point of $\mathrm{MCH}$ that was calculated based on the ROC (25 pg), complete concurrence between $\mathrm{MCH}$ and $\mathrm{CHr}$ reached $78.52 \%$ [Figure $4 \mathrm{a}$ ].

Using a cutoff point for $\mathrm{MCH}$ of $26 \mathrm{pg}$, complete concurrence between the two indices reached $82.96 \%$ [Figure $4 \mathrm{~b}$ ]. Furthermore, although MCH classified higher proportions of children into LID and IDA groups, it was able to diagnose all children with LID $(n=22)$ and all children with IDA ( $n=75)$ originally diagnosed by CHr [Table 11], which may imply a utility for $\mathrm{MCH}$ in screening for ID and IDA.

\begin{tabular}{|c|c|c|c|c|c|}
\hline & $\begin{array}{c}\text { Iron } \\
\text { sufficient } \\
(n=31), n(\%)\end{array}$ & $\begin{array}{c}\text { IDA } \\
(n=75) \\
n(\%)\end{array}$ & OR & $95 \% \mathrm{Cl}$ & $P$ \\
\hline \multicolumn{6}{|l|}{ Family members } \\
\hline 3 & $9(29.03)$ & $10(13.33)$ & 0.32 & $0.11-0.95$ & $0.04^{*}$ \\
\hline 4 & $7(22.58)$ & $14(18.66)$ & 0.85 & $0.2-1.72$ & 0.39 \\
\hline$\geq 5$ & I5 (48.39) & $51(68)$ & 1 & & \\
\hline \multicolumn{6}{|l|}{$\begin{array}{l}\text { Number of rooms } \\
\text { in house }\end{array}$} \\
\hline 1 & $6(19.36)$ & $18(24)$ & 0.57 & $0.15-2.18$ & 0.5 \\
\hline 2 & $20(64.5 I)$ & $3 I(4 I .33)$ & 0.29 & $0.09-0.90$ & $0.04 *$ \\
\hline$\geq 3$ & $5(16.13)$ & $26(34.66)$ & I & & \\
\hline \multicolumn{6}{|l|}{$\begin{array}{l}\text { Number of children } \\
\text { in family }\end{array}$} \\
\hline 1 & $10(32.26)$ & $13(17.33)$ & 0.33 & $0.11-0.96$ & $0.05^{*}$ \\
\hline 2 & $9(29.03)$ & $16(21.33)$ & 0.46 & $0.16-1.30$ & 0.17 \\
\hline$\geq 3$ & $12(38.7 \mathrm{I})$ & $46(6 I .33)$ & 1 & & \\
\hline \multicolumn{6}{|l|}{ Infants } \\
\hline Term infants & $31(100)$ & $70(93.33)$ & 0.2 & $0.01-3.79$ & 0.31 \\
\hline Preterm infants & 0 & $5(6.66)$ & & & \\
\hline \multicolumn{6}{|l|}{ Monthly family } \\
\hline$<10,000$ & $14(45.16)$ & $3 I(4 I .33)$ & 0.72 & $0.02-18.89$ & I \\
\hline $10,000-20,000$ & $17(54.84)$ & $43(57.33)$ & 0.82 & $\begin{array}{l}0.03- \\
21.35\end{array}$ & I \\
\hline$>20,000$ & 0 & I (I.33) & I & & \\
\hline \multicolumn{6}{|l|}{$\begin{array}{l}\text { Paternal educational } \\
\text { attainment }\end{array}$} \\
\hline Illiterate & 0 & 0 & & & \\
\hline Primary & $13(4 \mid .94)$ & $30(40)$ & 0.51 & $0.09-2.7 \mid$ & 0.7 \\
\hline Secondary & $12(38.7 \mid)$ & $30(40)$ & 0.55 & $0.1-2.95$ & 0.7 \\
\hline Higher & $4(12.90)$ & $6(8)$ & 0.33 & $0.04-2.43$ & 0.36 \\
\hline Institute/university & $2(6.45)$ & $9(12)$ & 1 & & \\
\hline \multicolumn{6}{|l|}{$\begin{array}{l}\text { Maternal } \\
\text { educational } \\
\text { attainment }\end{array}$} \\
\hline Illiterate & 0 & 0 & & & \\
\hline Primary & $15(48.39)$ & $30(40)$ & 3 & $0.45-19.94$ & 0.33 \\
\hline Secondary & $9(29.03)$ & $3 I(4 I .33)$ & 5.16 & $0.74-35.86$ & 0.1 \\
\hline Higher & $4(12.90)$ & $12(16)$ & 4.5 & $0.54-37.4$ & 0.28 \\
\hline Institute/university & $3(9.68)$ & $2(2.66)$ & I & & \\
\hline \multicolumn{6}{|l|}{ Type of delivery } \\
\hline Cesarean delivery & II (35.48) & $26(34.66)$ & 0.96 & $0.40-2.31$ & I \\
\hline Vaginal delivery & $20(64.5 I)$ & 49 (65.33) & & & \\
\hline \multicolumn{6}{|l|}{ Maternal smoking } \\
\hline Yes & $2(6.45)$ & $5(6.66)$ & 1.03 & $0.18-5.64$ & I \\
\hline No & $29(93.54)$ & 70 (93.33) & & & \\
\hline
\end{tabular}

\section{DISCUSSION}

Anemia reflects poor nutrition and poor health. ${ }^{[3]}$ The terms anemia, ID, and IDA are sometimes used interchangeably due to the fact that ID is commonly identified by the presence of anemia. ${ }^{[4]}$ IDA is a major contributor to the global burden of disease. ${ }^{[3]}$ The latest WHO report on the prevalence of anemia ${ }^{[15]}$ placed it as a moderate public health problem in children aged 6-59 months, with a prevalence of $37 \%$ (95\% confidence interval: 12\%-68\%), based on the estimates in 2011. 


\begin{tabular}{|c|c|c|c|}
\hline & $\begin{array}{c}\text { Before } \\
\text { management }\end{array}$ & $\begin{array}{c}\text { After } \\
\text { management }\end{array}$ & $P$ \\
\hline \multicolumn{4}{|c|}{$\begin{array}{l}4 \text { weeks after } \\
\text { management }(n=37)\end{array}$} \\
\hline $\mathrm{Hb}(\mathrm{g} / \mathrm{dL})$ & $9.7 I \pm 0.16$ & $10.67 \pm 0.15$ & $<0.0001 *$ \\
\hline HCT (\%) & $31.21 \pm 0.47$ & $34.42 \pm 0.50$ & $<0.000 I^{*}$ \\
\hline MCV (fL) & $67.03 \pm 1.46$ & $71.26 \pm 0.87$ & $0.015^{*}$ \\
\hline $\mathrm{MCH}(\mathrm{pg})$ & $21.48 \pm 0.43$ & $23.56 \pm 0.37$ & $0.0005^{*}$ \\
\hline $\mathrm{CHr}(\mathrm{pg})$ & $21.58 \pm 0.38$ & $24.82 \pm 0.26$ & $<0.0001 *$ \\
\hline $\begin{array}{l}\text { Platelets count } \\
\left(\times 10^{3} / \mu \mathrm{L}\right)\end{array}$ & $389,390 \pm 34,740$ & $334,874 \pm 31,914$ & 0.079 \\
\hline RDW (\%) & $16.99 \pm 0.44$ & $17.09 \pm 0.55$ & 0.917 \\
\hline $\begin{array}{l}\text { RBCs count } \\
\left(\times 10^{6} / \mu \mathrm{L}\right)\end{array}$ & $4.55 \pm 0.07$ & $4.80 \pm 0.08$ & $0.028 *$ \\
\hline \multicolumn{4}{|c|}{$\begin{array}{l}8 \text { weeks after } \\
\text { management }(n=I I)\end{array}$} \\
\hline $\mathrm{Hb}(\mathrm{g} / \mathrm{dL})$ & $8.82 \pm 0.31$ & $10.81 \pm 0.18$ & $<0.0001 *$ \\
\hline HCT (\%) & $29.12 \pm 1.12$ & $34.99 \pm 0.71$ & $0.0003^{*}$ \\
\hline MCV (fL) & $64.84 \pm 1.93$ & $71.74 \pm 1.27$ & $0.007^{*}$ \\
\hline $\mathrm{MCH}(p g)$ & $19.9 \pm 0.82$ & $23.38 \pm 0.72$ & $0.005^{*}$ \\
\hline $\mathrm{CHr}(\mathrm{pg})$ & $20.53 \pm 0.88$ & $25.38 \pm 0.35$ & $0.0002 *$ \\
\hline $\begin{array}{l}\text { Platelets count } \\
\left(\times 10^{3} / \mu \mathrm{L}\right)\end{array}$ & $436,000 \pm 52,744$ & $375,429 \pm 43,939$ & 0.39 \\
\hline RDW (\%) & $|7.3| \pm 0.50$ & $16.53 \pm 0.76$ & 0.4 \\
\hline $\begin{array}{l}\text { RBCs count } \\
\left(\times 10^{6} / \mu \mathrm{L}\right)\end{array}$ & $4.477 \pm 0.10$ & $4.906 \pm 0.09$ & $0.006 *$ \\
\hline
\end{tabular}

Beginning in 2011, the ongoing war in Syria continues to damage the lives of Syrian children. Due to war, many children are suffering from malnutrition ${ }^{[12]}$ which may potentially raise the prevalence of all malnutrition-related disorders, including IDA. Our study points out the high prevalence of anemia in a sample of children visiting a major outpatient center in Damascus. This prevalence was high compared to that of similar regional and international studies. ${ }^{[16-22]}$

Both LID and IDA are associated with a group of clinical manifestation that is caused by decreased oxygen transport to tissues and organs and a decrease of iron in serum, leading to a regression in biological functions. Investigating such manifestations in our study sample revealed that more than one-third of children with ID, with or without anemia, have irritability (37\%) and mood swings (36\%). Furthermore, loss of appetite was prevalent in $24 \%$ of children. This usually worsens anemia and necessitates rapid nutritional intervention to meet the iron requirements needed to correct ID and anemia. Anemia might also be associated with a craving to eat nonnutritive substances such as dirt and snow, which is known as Pica syndrome, which is more common in children and among lower socioeconomic classes. ${ }^{[23]}$ In our study, Pica syndrome was prevalent in $12.5 \%$ of children

\begin{tabular}{|c|c|c|c|c|c|}
\hline & $\begin{array}{l}\text { Cutoff } \\
\text { point }\end{array}$ & $\begin{array}{c}\text { Sensitivity } \\
\text { (\%) }\end{array}$ & $\begin{array}{c}\text { Specificity } \\
(\%)\end{array}$ & AUC & OR \\
\hline \multicolumn{6}{|l|}{ For LID } \\
\hline Ferritin $(\mathrm{ng} / \mathrm{mL})$ & 27.25 & 56.10 & 57.14 & 0.564 & 1.31 \\
\hline TSAT (\%) & 4.22 & 58.97 & 60 & $0.74 I$ & $\mathrm{I} .47$ \\
\hline $\mathrm{MCV}(\mathrm{fL})$ & 75.70 & 68.75 & 68.75 & 0.779 & 2.2 \\
\hline $\mathrm{MCH}(\mathrm{pg})$ & 25.45 & 82.61 & 80 & 0.910 & 4.13 \\
\hline RDW (\%) & 15 & 71.43 & 75 & 0.739 & 2.86 \\
\hline $\begin{array}{l}\text { Platelets count } \\
\left(\times \mid 0^{3} / \mu \mathrm{L}\right)\end{array}$ & 441500 & 54.79 & 55.56 & 0.543 & 1.23 \\
\hline $\begin{array}{l}\text { Serum iron } \\
(\mathrm{mmol} / \mathrm{L})\end{array}$ & 4.5 & 70.21 & 66.67 & 0.781 & 2.11 \\
\hline TIBC $(\mu \mathrm{mol} / \mathrm{L})$ & 73.50 & 53.85 & 60 & 0.612 & 1.35 \\
\hline \multicolumn{6}{|l|}{ For IDA } \\
\hline Ferritin $(\mathrm{ng} / \mathrm{mL})$ & 26.05 & 58.06 & 57.14 & 0.589 & 1.35 \\
\hline TSAT (\%) & 3.63 & 58.62 & 60 & 0.782 & 1.47 \\
\hline MCV (fL) & 74.45 & 87.84 & 90 & $0.94 I$ & 8.78 \\
\hline $\mathrm{MCH}(\mathrm{pg})$ & 25.10 & 88.57 & 90 & 0.953 & 8.86 \\
\hline RDW (\%) & 15.25 & 76.27 & 75 & 0.807 & 3.05 \\
\hline $\begin{array}{l}\text { Platelets count } \\
\left(\times 10^{3} / \mu \mathrm{L}\right)\end{array}$ & 447000 & 53.57 & 51.85 & 0.533 & I.II \\
\hline $\begin{array}{l}\text { Serum iron } \\
(\mathrm{mmol} / \mathrm{L})\end{array}$ & 3.5 & 62.86 & 77.78 & 0.807 & 2.82 \\
\hline TIBC $(\mu \mathrm{mol} / \mathrm{L})$ & 76.50 & 62.07 & 60 & 0.569 & 1.55 \\
\hline \multicolumn{6}{|c|}{$\begin{array}{l}\text { Significant at the } 0.05 \text { level. MCV: Mean corpuscular volume, MCH: Mean corpuscular } \\
\text { hemoglobin, TIBC:Total iron-binding capacity, TSAT:Transferrin saturation, RDW: Red } \\
\text { cell distribution width,AUC:Area under the curve, OR: Odds ratio, LID: Latent iron } \\
\text { deficiency, IDA: Iron deficiency anemia }\end{array}$} \\
\hline
\end{tabular}

with ID, with or without anemia. Although such symptoms are very subjective and could be caused by factors other than ID, like war stressors in Syria, we preferred to investigate them to shed light on the symptomatic aspects of ID.

ID can be disastrous in infancy and early childhood. It may cause defected mental and motor development that might not be reversible by subsequent iron therapy. ${ }^{[4]}$ One goal of the prospective study was to assess the effects of ID on children's development. Hence, we planned to follow their growth over time by recording their length, weight, and head circumference at follow-up visits on growth charts. However, we could obtain such values for only one time due to a low percentage of parents who adhered to follow-up visits, which may be caused by weak health awareness and/or the country's circumstances during the Syrian crisis. Despite the limited data, the study revealed that prevalence of abnormalities in weight-to-age ratio was significantly higher in children with LID $(P=0.04)$ and with IDA $(P=0.05)$ compared to nonanemic children.

\section{Factors affecting prevalence of iron deficiency and iron deficiency anemia}

In developing countries, infant diets tend to be low in iron due to lower consumption of iron-fortified and/or 


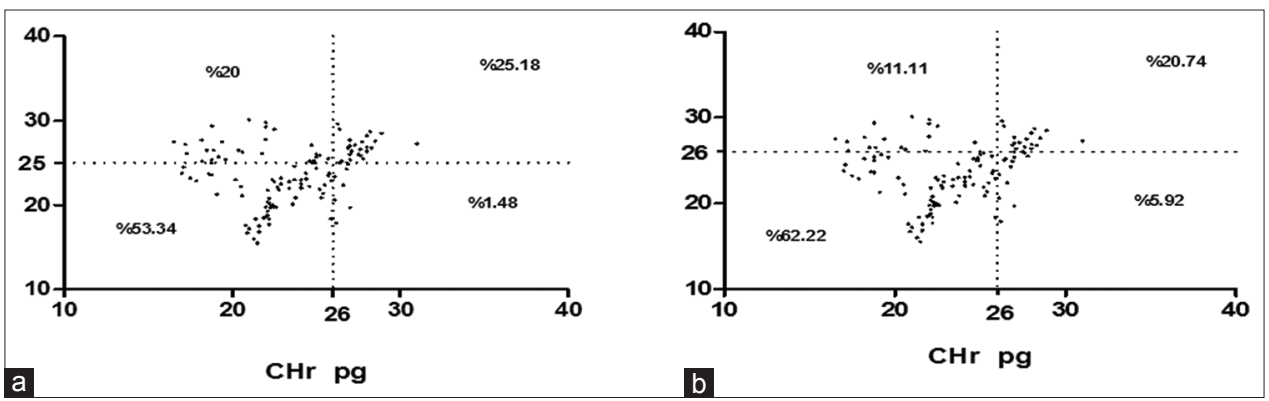

Figure 4: Diagnostic ability of mean corpuscular hemoglobin, using 25 pg cutoff value (a) and 26 pg cutoff value (b), compared to reticulocyte hemoglobin content (prospective study)

\begin{tabular}{|c|c|c|c|c|c|c|c|c|c|c|c|}
\hline & $\mathrm{Hb}$ & HCT & MCV & $\mathrm{MCH}$ & RBCs count & $\mathrm{CHr}$ & RDW & Platelets count & Serum iron & Ferritin & TIBC \\
\hline \multicolumn{12}{|l|}{$\mathrm{Hb}$} \\
\hline HCT & $0.860 *$ & & & & & & & & & & \\
\hline $\mathrm{MCV}$ & $0.676 *$ & $0.553^{*}$ & & & & & & & & & \\
\hline $\mathrm{MCH}$ & $0.74 I^{*}$ & $0.397 *$ & $0.770 *$ & & & & & & & & \\
\hline RBCs count & $0.158^{\circ}$ & $0.466^{*}$ & $-0.328^{\S}$ & $-0.534^{*}$ & & & & & & & \\
\hline $\mathrm{CHr}$ & $0.707^{*}$ & $0.415^{*}$ & $0.659 *$ & $0.857^{*}$ & $-0.376^{*}$ & & & & & & \\
\hline RDW & $-0.626 *$ & $-0.472 *$ & $-0.537^{*}$ & $-0.658 *$ & $0.202^{\S}$ & $-0.448 *$ & & & & & \\
\hline Platelets count & -0.054 & 0.007 & -0.014 & $-0.040^{\circ}$ & $0.050^{\circ}$ & "0.09ו" & $0.046^{\circledR}$ & & & & \\
\hline Serum iron & $0.091^{\pi}$ & $0.066^{\pi}$ & $0.270^{\S}$ & $0.363^{\S}$ & $-0.176^{\circ}$ & $0.326^{\S}$ & $0.003^{\circ}$ & $0.06 I^{\pi}$ & & & \\
\hline Ferritin & $0.206^{\pi}$ & $0.245^{\pi}$ & $0.033^{\prime \prime}$ & $0.024^{\pi}$ & $0.296^{\S}$ & $-0.05 \mathrm{I}^{\pi}$ & $-0.147^{\prime}$ & $-0.225^{\circ}$ & $0.239^{\circ}$ & & \\
\hline TIBC & $-0.254^{\pi}$ & $-0.083^{\text {I }}$ & $-0.366^{\S}$ & $-0.499^{\S}$ & $0.303^{\pi}$ & $-0.272^{\text {व }}$ & $0.173^{\circ}$ & $0.072^{\pi}$ & $-0.161^{\pi}$ & $-0.234^{\circ}$ & \\
\hline
\end{tabular}

\begin{tabular}{|c|c|c|c|c|}
\hline \multicolumn{5}{|c|}{$\begin{array}{l}\text { Table I I: Prevalence of latent iron deficiency } \\
\text { and iron deficiency anemia in study sample using } \\
\text { reticulocyte hemoglobin content and mean corpuscular } \\
\text { hemoglobin }(n=135)\end{array}$} \\
\hline & Iron sufficient (\%) & ID (\%) & LID (\%) & IDA (\%) \\
\hline & 28.15 & & & 55.55 \\
\hline Using $\mathrm{MCH}$ & 23.33 & 76.67 & 19.17 & 57.5 \\
\hline
\end{tabular}

MCH: Mean corpuscular hemoglobin, $\mathrm{CHr}$ : Reticulocyte hemoglobin content, LID: Latent iron deficiency, IDA: Iron deficiency anemia, ID: Iron deficiency

animal-derived food. ${ }^{[10]}$ Many demographic factors, such as age, gender, and socioeconomic status, play a major role in the prevalence of ID. ${ }^{[4]}$ The retrospective study did not reveal any statistically significant differences in the prevalence of anemia between male and female children who are 4 months to 11 years old and between children whose families live in cities and those living in suburbs. This may indicate that anemia in the study sample is a general nutritional problem that is irrelevant to gender or place of residence. However, the prevalence of anemia was higher (74\%) in the oldest children group (12-14 years), and female children showed statistically significant $(P=0.03)$ higher prevalence of anemia $(24 / 27,88.9 \%)$, as compared with male children $(19 / 31,61.3 \%)$. This can be attributed to a physiological reason as adolescent girls are expected to be more prone to IDA due to monthly loss of blood during menstruation. Intriguingly, the prevalence of LID in the prospective study was significantly higher in male children compared to female children $(P=0.004)$, indicating the need for further investigation of gender effects on ID. Furthermore, the prospective study revealed differences in prevalence of IDA in infants who live in suburbs and those living in cities (the prevalence was higher in suburbs), indicating the need to further investigate the possible causes for such discrepancy, which could include differences present in parents' level of educational and health awareness, and the lack of adequate health guidance in suburbs. In addition, because it is common to raise cows in the Syrian suburbs, relying on cow's milk as a primary source of nutrition for children could contribute to the increased prevalence of LID and IDA in infants of suburb families.

It is known that ID is most common among those with low socioeconomic status, ${ }^{[4]}$ possibly due to differences in type and content of diet. The socioeconomic status for families plays an important role in the healthcare offered for children. For example, low familial income leads to a decrease in the diversity of the daily food intake, resulting in a lack of iron-rich food, especially heme iron. This would negatively affect iron status and $\mathrm{Hb}$ concentration in children and subsequently cause LID, which may develop to IDA if not managed. However, our study did not reveal any significant effect of family income on prevalence of LID and IDA in children. This could be explained by the 
fact that the vast majority of children in this study were from poor- and middle-class families as the mean monthly income of included families did not exceed 20,000 Syrian Pound $(<50 \$)$.

A lower prevalence of ID is expected in children for families with higher income and upper educational level for parents, due to their higher health awareness and capability for provision of healthier diet for their children. Vice versa, lower educational levels for parents lead to lower awareness regarding health and healthy diets for children, subsequently leading to nutritional diseases in children, such as IDA. However, there was no significant relationship between parents' educational level and the prevalence of LID and IDA in our study. This may suggest that the income of families is probably the major determinant of the health of their children.

ID results from long-term negative iron balance. ${ }^{[4]}$ The increased prevalence of LID in infants can be ascribed to the misappropriation between growth-related iron requirements and nutritional iron intake. Infants who are primarily fed by maternal or cow's milk are at increased risk of ID as compared to those who are fed by iron-fortified or iron-enriched formula. This is due to the low levels of iron in maternal and cow's milk. For this reason, it is recommended to provide iron supplements to healthy infants who are exclusively breastfed during a period from 6 to 12 months of age. ${ }^{[13]}$ Our study did not show any statistically significant differences in the prevalence of LID or IDA between children who consume iron-fortified formula and those who depended on noniron-fortified milk (exclusive breastfeeding, cow milk, or both). This finding should raise questions concerning the effectiveness of commercial iron-fortified formulas available in the Syrian markets during the study period (iron content and bioavailability) and highlights the need for further investigation to ensure its compliance with specifications and its effectiveness in preventing ID in infants and children. It is worth mentioning that the increased prices of imported children's foods, or the absence of such foods in the Syrian markets, during the period of the Syrian crisis might contribute to parents' inability to provide such forms of iron-fortified foods for their children. In addition, inappropriate mix of milk/formula by adding more water to extend the amount of the child's meal is another possibility for the present findings.

\section{Management of iron deficiency}

Recommendations concerning dose, content, period, and follow-up of iron treatment differs widely in the medical literature. ${ }^{[24]}$ Oral iron therapy, using ferrous sulfate (elemental iron), is generally preferred due to lower cost and lesser side effects. ${ }^{[24]}$ For infants and children, a dose of 3-6 mg/kg should be given daily. ${ }^{[24,25]}$ With successful therapy, $\mathrm{Hb}$ levels are expected to rise by about $20 \mathrm{~g} / \mathrm{L}(2 \mathrm{~g} / \mathrm{dL})$ every 3 weeks. ${ }^{[25]}$ Failure to respond to iron therapy is often caused by poor compliance with medication, continuous bleeding, or malabsorption. ${ }^{[24,25]}$ It is important to reevaluate those who do not respond to therapy to exclude other causes for microcytic anemia. For example, many patients with thalassemia trait or sideroblastic anemia are treated with iron before performing $\mathrm{Hb}$ studies, bone marrow studies, or other studies that would have revealed the correct diagnosis.

In the prospective study, $\mathrm{Hb}$ and $\mathrm{CHr}$ significantly increased after 4 weeks and 8 weeks of management compared to baseline measurements. However, the increase in mean $\mathrm{Hb}$ was only $0.96 \mathrm{~g} / \mathrm{dL}$ after 4 weeks and $1.99 \mathrm{~g} / \mathrm{dL}$ after 8 weeks of therapy. Furthermore, 4 weeks after management, mean $\mathrm{Hb}$ did not reach the normal level $(11 \mathrm{~g} / \mathrm{dl})$, indicating that those children needed a longer management period. Noncompliance with the medical management and the variation in severity of IDA among subjects may be responsible for such observation.

\section{Diagnosis}

For diagnosing ID, with or without anemia, many laboratories in Syria depend on a number of hematological and biochemical indices (i.e., ferritin, TSAT, and TIBC), which have many limitations, such as being affected by the time of blood sampling (day or night) and the presence of inflammatory processes or cancers. This study suggests the unreliability on any of these traditional indices for diagnosing LID in children due to their relatively low sensitivity and specificity in diagnosing LID, in addition to showing poor correlation with $\mathrm{CHr}$.

Comparing the investigated hematological and biochemical indices between children classified as normal, iron deficient with no anemia (LID), and IDA showed a decrease in the values of $\mathrm{Hb}, \mathrm{HCT}, \mathrm{MCV}, \mathrm{MCH}$, serum iron, and TSAT in children with LID and IDA compared to nonanemic children, while no statistically significant differences in ferritin and TIBC were observed. On the contrary, ferritin was relatively higher in children with IDA compared to nonanemic children. Looking back at children with IDA, only $22.86 \%$ of them had ferritin concentrations below $7 \mathrm{ng} / \mathrm{dl}$, which indicate depleted iron stores. Furthermore, ROC analysis suggests ferritin cutoff points of $27.25 \mathrm{ng} / \mathrm{ml}$ for diagnosing LID and $26.05 \mathrm{ng} / \mathrm{ml}$ for diagnosing IDA [Table 9]. Those two values exceed double the reference cutoff value $(12 \mathrm{ng} / \mathrm{ml})$ for diagnosing IDA in children 
younger than 5 years. This result highlights the need to reconsider using serum ferritin concentration as a marker of iron stores, especially in infants and children. Ferritin, an acute phase reactant, may increase in case of inflammation or infection. It is recommended to measure C-reactive protein when measuring serum ferritin to exclude inflammatory status. ${ }^{[13,26]}$

The two most sensitive hematological indices for ID are $\mathrm{MCV}$ and $\mathrm{MCH} .{ }^{[4]}$ This was compatible with our study which showed that MCV and MCH had the highest sensitivity and specificity in diagnosing IDA. Furthermore, a high correlation between $\mathrm{Hb}$ and both $\mathrm{MCV}$ and $\mathrm{MCH}$ was shown in this study, pointing out the usefulness of those two markers in diagnosing IDA. MCH showed the highest correlation with $\mathrm{CHr}$ and had the highest sensitivity and specificity in diagnosing IDA. Moreover, $\mathrm{MCH}$ does not require any additional costs or special equipment and is a component of routine $\mathrm{CBC}$. Therefore, we investigated the possibility of using $\mathrm{MCH}$ in diagnosing IDA and LID as an alternative to $\mathrm{CHr}$, which requires imported reagents and instrumentation (i.e., flow cytometer) that might not be available in all clinical laboratories, especially in rural areas in Syria. There was a complete concurrence between $\mathrm{MCH}$ and $\mathrm{CHr}$ in more than $75 \%$ of cases. Since $\mathrm{MCH}$ and $\mathrm{CHr}$ have a similar concept for calculation but with an essential difference in the maturation of the red blood cells (RBCs) (reticulocytes in $\mathrm{CHr}$ and mature RBCs in $\mathrm{MCH}$ ), we investigated the use of the recommended reference cutoff point of $\mathrm{CHr}(26 \mathrm{pg})$ as a cutoff point for $\mathrm{MCH}$ in diagnosing ID. Using this cutoff point, the complete concurrence between $\mathrm{MCH}$ and $\mathrm{CHr}$ almost reached $83 \%$. Furthermore, $\mathrm{MCH}$ was able to identify all cases of LID and IDA that were identified by $\mathrm{CHr}$. These results point out a potentially useful screening application for $\mathrm{MCH}$ in diagnosing anemia.

\section{Strengths and limitations}

Although we could not collect data in the past months due to lack of fund and the hardships of conducting research in a conflict zone, this study is the only one to investigate anemia among the Syrian population during the war; it can serve as a reference for the present clinical practice and guidance for future studies. In addition, besides epidemiology, our results have implications in the diagnosis and treatment of ID and IDA.

In terms of limitations, our sample did not include patients from private clinics that could treat families with higher socioeconomic status. The low socioeconomic status for visitors to the Children's Hospital in Damascus may contribute to the high prevalence of LID and IDA revealed in this study. In addition, as the only center for recruiting participants was located in Damascus, participants included in the study mainly represent individuals from Damascus city and Damascus's suburbs, along with displaced people who were relocated to these areas. Children of other Syrian cities and governorates might possibly have different characteristics that affect their iron status, limiting the generalizability of the results; higher rates are expected in displaced infants and in remote regions of the country. Another important limitation is the short follow-up period for iron-deficient patients who were given oral iron replacements, and the small number of participants who could be followed up, limiting the ability to observe the long-term efficacy of the management. In addition, it is important to implement the conclusions of the diagnostic part with caution as our findings apply to our population of interest, apparently healthy children and might be different for children with chronic diseases or inflammatory states; we recommend conducting similar studies with larger samples, including children from other governorates of Syria.

\section{CONCLUSION}

The study reveals a high prevalence of LID and IDA among apparently healthy children who visit the outpatient clinics of the Children's Hospital in Damascus, Syria. This is significant as ID, if not managed, may lead to short- and long-term motor and neurological complications. The study also points out the limited capability of conventional hematological and biochemical indices (such as ferritin) to diagnose LID and IDA compared to $\mathrm{CHr}$ in those patients and opens doors for further investigating the role of $\mathrm{MCH}$ in screening for ID in children.

Due to its disastrous consequences, several approaches have been proposed to control and prevent IDA in infants and young children of developing countries. Such approaches span from paying attention to maternal health to using universal iron supplements for children..$^{[4,10,27,28]}$ Our study points out the need for implementing effective measures to control and prevent ID in Syria and in countries with similar conditions. This could be achieved with collaborative national and international efforts to provide iron supplementation and paying more attention to other existing malnutrition cases in this area.

\section{Acknowledgment}

We greatly thank all physicians, nurses, and lab staff at the Children's Hospital, Damascus University, Damascus, who facilitated the conduct of this project. 


\section{Financial support and sponsorship}

The study was entirely supported by the Faculty of Pharmacy, Damascus University, Damascus, Syria.

\section{Conflicts of interest}

There are no conflicts of interest.

\section{REFERENCES}

1. Kassebaum NJ, Jasrasaria R, Naghavi M, Wulf SK, Johns N, Lozano R, et al. A systematic analysis of global anemia burden from 1990 to 2010. Blood 2014;123:615-24.

2. McLean E, Cogswell M, Egli I, Wojdyla D, de Benoist B. Worldwide prevalence of anaemia, WHO vitamin and mineral nutrition information system, 1993-2005. Public Health Nutr 2009;12:444-54.

3. De Benoist B, McLean E, Egli I, Cogswell M, Cogswell M. WHO Global Database on Anaemia. Geneva: World Health Organization; 2008. p. 1993-2005.

4. World Health Organization. Iron Deficiency Anaemia: Assessment, Prevention and Control: A Guide for Programme Managers. World Health Organization; 2001.

5. Leung AK, Chan KW. Iron deficiency anemia. Adv Pediatr 2001;48:385-408.

6. Walter T, De Andraca I, Chadud P, Perales CG. Iron deficiency anemia: Adverse effects on infant psychomotor development. Pediatrics 1989;84:7-17.

7. DeMaeyer EM, Hallberg L, Gurney JM, Sood S, Dallman P, Srikantia S, et al. Preventing and Controlling Iron Deficiency Anaemia through Primary Health Care: A Guide for Health Administrators and Programme Managers. WHO: Geneva; 1989.

8. Simon-Lopez R. Methods of Determination of Iron Deficiency and Hemochromatosis. Google Patents; 2012.

9. Brugnara C, Zurakowski D, DiCanzio J, Boyd T, Platt O. Reticulocyte hemoglobin content to diagnose iron deficiency in children. JAMA 1999;281:2225-30.

10. Yip R, Ramakrishnan U. Experiences and challenges in developing countries. J Nutr 2002;132:827S-30S.

11. Ben Taleb Z, Bahelah R, Fouad FM, Coutts A, Wilcox M, Maziak W, et al. Syria: Health in a country undergoing tragic transition. Int J Public Health 2015;60 Suppl 1:S63-72.

12. Devakumar D, Birch M, Rubenstein LS, Osrin D, Sondorp E, Wells JC, et al. Child health in Syria: Recognising the lasting effects of warfare on health. Confl Health 2015;9:34.

13. Baker RD, Greer FR, Committee on Nutrition American Academy of Pediatrics. Diagnosis and prevention of iron deficiency and iron-deficiency anemia in infants and young children (0-3 years of age). Pediatrics 2010;126:1040-50.

14. World Health Organization. Haemoglobin Concentrations for the Diagnosis of Anaemia and Assessment of Severity. World Health Organization; 2011.

15. World Health Organization. The Global Prevalence of Anaemia in 2011. World Health Organization; 2015.

16. Chandyo RK, Ulak M, Adhikari RK, Sommerfelt H, Strand TA. Prevalence of iron deficiency and anemia among young children with acute diarrhea in Bhaktapur, Nepal. Healthcare (Basel) 2015;3:593-606.

17. Al Hawsawi ZM, Al-Rehali SA, Mahros AM, Al-Sisi AM, Al-Harbi KD, Yousef AM, et al. High prevalence of iron deficiency anemia in infants attending a well-baby clinic in Northwestern Saudi Arabia. Saudi Med J 2015;36:1067-70.

18. Heath AL, Tuttle CR, Simons MS, Cleghorn CL, Parnell WR. Longitudinal study of diet and iron deficiency anaemia in infants during the first two years of life. Asia Pac J Clin Nutr 2002;11:251-7.

19. Tympa-Psirropoulou E, Vagenas C, Dafni O, Matala A, Skopouli F. Environmental risk factors for iron deficiency anemia in children 12-24 months old in the area of Thessalia in Greece. Hippokratia 2008; $12: 240-50$.

20. Vendt N, Grünberg H, Leedo S, Tillmann V, Talvik T. Prevalence and causes of iron deficiency anemias in infants aged 9 to 12 months in Estonia. Medicina (Kaunas) 2007;43:947-52.

21. Zlotkin SH, Ste-Marie M, Kopelman H, Jones A, Adam J. The prevalence of iron depletion and iron-deficiency anaemia in a randomly selected group of infants from four Canadian cities. Nutr Res 1996;16:729-33.

22. Monajemzadeh SM, Zarkesh MR. Iron deficiency anemia in infants aged 12-15 months in Ahwaz, Iran. Indian J Pathol Microbiol 2009;52:182-4.

23. Khan Y, Tisman G. Pica in iron deficiency: A case series. J Med Case Rep 2010;4:86.

24. Özdemir N. Iron deficiency anemia from diagnosis to treatment in children. Turk Pediatri Ars 2015;50:11-9.

25. Pasricha SR, Flecknoe-Brown SC, Allen KJ, Gibson PR, McMahon LP, Olynyk JK, et al. Diagnosis and management of iron deficiency anaemia: A clinical update. Med J Aust 2010;193:525-32.

26. Thurnham DI, McCabe LD, Haldar S, Wieringa FT, Northrop-Clewes CA, McCabe GP, et al. Adjusting plasma ferritin concentrations to remove the effects of subclinical inflammation in the assessment of iron deficiency: A meta-analysis. Am J Clin Nutr 2010;92:546-55.

27. Lutter CK. Iron deficiency in young children in low-income countries and new approaches for its prevention. J Nutr 2008;138:2523-8.

28. Pasricha SR, Drakesmith H, Black J, Hipgrave D, Biggs BA. Control of iron deficiency anemia in low- and middle-income countries. Blood 2013;121:2607-17 